\title{
Hospitalization for Myocardial Infarction with Ticagrelor or Clopidogrel in Patients with Acute Coronary Syndrome: An On-Treatment Comparative Effectiveness Analysis
}

\author{
Tope Olufade $\cdot$ Nipun Atreja • Narinder Bhalla $\cdot$ John Venditto • \\ Durgesh Bhandary · Kaushik Chafekar · David Cobden • \\ Naeem D. Khan
}

Received: January 20, 2021 / Accepted: July 27, 2021 / Published online: August 13, 2021

(c) The Author(s) 2021

\section{ABSTRACT}

Introduction: Prescribing patterns and suboptimal adherence present methodological challenges for real-world head-to-head comparisons of ticagrelor and clopidogrel in intent-to-treat studies. The aim of this study was to compare ticagrelor and clopidogrel in an on-treatment population.

Methods: This retrospective cohort study used the Optum $^{\mathrm{TM}}$ Clinformatics ${ }^{\mathrm{TM}}$ database to identify patients with acute coronary syndrome (ACS) discharged on ticagrelor or clopidogrel between January 1, 2012 and September 30, 2019. The primary end point was hospitalization for myocardial infarction (MI); the secondary end point was hospitalization for major bleeding. The ticagrelor and clopidogrel cohorts were balanced by propensity score matching (PSM) 1:3 for demographic and clinical characteristics. Outcomes were ascertained from day 31 until day 365 or end of follow-up.

Supplementary Information The online version contains supplementary material available at https:// doi.org/10.1007/s40119-021-00236-4.

T. Olufade $(\bowtie) \cdot$ N. Atreja $\cdot$ N. Bhalla $\cdot$ J. Venditto D. Bhandary $\cdot$ D. Cobden $\cdot$ N. D. Khan

AstraZeneca, Wilmington, DE, USA

e-mail: tope.olufade@astrazeneca.com

K. Chafekar

ZS Associates India Pvt. Ltd., Pune, Maharashtra, India
Results: Of 339,387 patients with ACS, 14,110 ticagrelor- and 57,482 clopidogrel-treated patients met the study criteria. After PSM, 13,373 ticagrelor- and 29,656 clopidogrel-treated patients provided 4945 and 13,895 patientyears of data, respectively, for the primary end point. Hospitalization for MI was significantly lower in the ticagrelor compared to the clopidogrel cohort (2.22 vs. 3.52 per 100 patientyears; $36.8 \%$ relative risk reduction [RRR]; $P<0.0001)$. Hospitalization for major bleeding was similar in the ticagrelor and clopidogrel cohorts (2.04 vs. 2.06 per 100 patient-years; $1.1 \%$ RRR, $P=0.9214)$.

Conclusions: In this real-world on-treatment analysis, hospitalization for MI was significantly lower with ticagrelor compared to clopidogrel, with similar rates of hospitalization for major bleeding. Study findings underscore the importance of being on the appropriate guidelinerecommended therapy and support the use of ticagrelor over clopidogrel.

Keywords: Acute coronary syndromes; Anti platelet therapy; Comparative effectiveness; Clopidogrel; Dual antiplatelet therapy; Myocardial infarction; Outcomes; Ticagrelor 


\section{Key Summary Points}

Why carry out this study?

Prescribing patterns and suboptimal adherence present methodological challenges for intent-to-treat observational studies; therefore, results from real-world studies comparing ticagrelor and clopidogrel in patients with acute coronary syndrome (ACS) have been inconsistent.

This retrospective cohort study compared hospitalization for myocardial infarction (MI) and hospitalization due to major bleeding in an on-treatment population of patients with ACS discharged on ticagrelor or clopidogrel.

\section{What was learned from the study?}

A significant $36.8 \%$ relative risk reduction in hospitalization for MI between days 31 and 365 after discharge was seen with ticagrelor compared with clopidogrel among propensity score-matched cohorts of on-treatment patients; there was no significant difference in hospitalization due to major bleeding.

This is the first on-treatment analysis with the primary objective of comparing hospitalization for MI after an ACS with ticagrelor and clopidogrel in a contemporary US ACS patient population in a real-world setting.

The findings of this study support the use of ticagrelor over clopidogrel as part of dual antiplatelet therapy (DAPT) for patients with ACS and underscore the importance of adherence and persistence with DAPT.

\section{INTRODUCTION}

Acute coronary syndrome (ACS) is a significant cause of morbidity and mortality worldwide. There were more than 1 million unique hospitalizations for ACS in the United States (US) in 2016 [1]. Patients with a history of ACS have an increased long-term risk of recurrent major adverse cardiovascular events (MACE), including myocardial infarction (MI), and 1-year mortality [2, 3]. Dual antiplatelet therapy (DAPT) with aspirin and a P2Y12 inhibitor for at least 12 months (6-12 months for patients with increased bleeding risk) has been shown to reduce the risk of recurrent cardiovascular events [4].

Ticagrelor is a direct-acting and reversible P2Y12 inhibitor with more potent antiplatelet activity than clopidogrel $[5,6]$. DAPT with ticagrelor in preference to clopidogrel in combination with aspirin is recommended in current ACS guidelines from the American College of Cardiology/American Heart Association (class IIa) and the European Society of Cardiology, based on the results of the PLATO trial $[4,7,8]$. This randomized, double-blind trial in 18,624 patients with ACS, with or without ST-segment elevation, demonstrated a significant reduction in the risk of the composite end point of death due to vascular causes, MI, or stroke at 12 months with ticagrelor compared with clopidogrel (9.8 vs. $11.7 \%$; hazard ratio [HR] $0.84,95 \%$ CI $0.77-0.92 ; P<0.001)$. There were also significant reductions with ticagrelor vs. clopidogrel in the rates of the prespecified secondary end points of death from any cause, MI, or stroke (10.2 vs. $12.3 \%$; HR $0.84,95 \%$ CI $0.77-0.92 ; P<0.001$ ), MI alone (5.8 vs. $6.9 \%$; HR $0.84,95 \%$ CI $0.75-0.95 ; P=0.005)$, and death from vascular causes $(4.0$ vs. $5.1 \%$; HR $0.79,95 \%$ CI $0.69-0.91 ; P=0.001$ ) [9]. There was no significant difference in overall PLATO major bleeding; however, PLATO non-coronary artery bypass graft-related major bleeding was increased with ticagrelor compared with clopidogrel $(P=0.03)$ [9].

Ticagrelor and clopidogrel have also been compared in real-world studies in patients with ACS, although the results for these intention-to- 
treat (ITT) observational studies have been inconsistent. The benefit of ticagrelor compared with clopidogrel was demonstrated in a large real-world population of ACS patients treated over 24 months in the SWEDEHEART study [10]. In this ITT prospective cohort study, 45,073 patients were analyzed based on whether ticagrelor was prescribed on discharge [10]. The intended duration of DAPT with ticagrelor and aspirin at discharge was 12 months in $83.8 \%$ of patients and $<12$ months in $7.1 \%$ [10]. Ticagrelor was associated with a lower adjusted risk of the composite end point of allcause mortality or rehospitalization for MI or stroke compared with clopidogrel (HR 0.85, 95\% CI 0.78-0.93) [10].

ITT methodologies in observational studies have inherent limitations, including that patient classification uses baseline treatment assignment, but outcome assessments occur later, at which point patients may have switched treatments $[11,12]$. Bias may occur when treatment switching occurs more frequently in one group than others, treatment adherence varies among groups, confounders are not properly considered, or treatment duration varies depending on outcome [11, 12].

Differences in outcomes among ITT observational studies may reflect these methodological limitations. For example, a retrospective ITT analysis in 11,185 patients with ACS who underwent percutaneous coronary intervention (PCI) classified patients according to prescribed P2Y12 inhibitor treatment had findings that were discordant with those of SWEDEHEART as well as the PLATO trial, which included medically managed patients as well as those who underwent PCI [13]. In this study, a higher proportion of patients in the ticagrelor cohort than in the clopidogrel cohort switched treatments (14.0 and 2.3\%, respectively) and most (91\%) of the patients switching from ticagrelor to clopidogrel did so prior to a MACE, whereas only $57 \%$ of patients who switched from clopidogrel did so before a MACE [13]. The study did not find a reduced risk of the primary composite outcome of all-cause death, hospitalization for nonfatal ACS, coronary revascularization (excluding planned staged PCI) or stent thrombosis within 365 days after the index hospitalization, with ticagrelor compared with clopidogrel after multivariable adjustment (adjusted HR 0.97, 95\% CI 0.85-1.10) [13].

Given the limitations of ITT analyses in observational studies, the aim of this study was to compare the incidence of hospitalization for MI in an on-treatment population of patients with ACS receiving post-discharge treatment with either ticagrelor or clopidogrel in realworld clinical practice.

\section{METHODS}

This was a retrospective, observational cohort study using real-world data from patients treated with ticagrelor or clopidogrel following hospitalization for an ACS event. Data were obtained from the Optum ${ }^{\mathrm{TM}}$ Clinformatics $^{\mathrm{TM}}$ Data Mart (Optum CDM) database, a closed system of de-identified health claims data for patients with commercial or Medicare Advantage coverage from a large national US health insurer. The database includes summary information on inpatient hospital stays and information on services performed in an inpatient setting, which were used to identify hospitalizations for MI. This analysis used patient-level data on diagnoses, prescriptions, place of service (inpatient hospitalizations), and procedures from January 1, 2011 to September 30, 2019.

Institutional Review Board approval and written informed consent from patients were not required because this study used only de-identified claims data. The data source for this study was the Optum ${ }^{\mathrm{TM}}$ Clinformatics ${ }^{\mathrm{TM}}$ database, which can be accessed by license from Optum (https://www.optum.com/business/ solutions/life-sciences.html).

\section{Eligibility Criteria}

The study included patients with ACS, identified by International Classification of Diseases, Ninth Revision, Clinical Modification (ICD-9 CM) and International Classification of Diseases, Tenth Revision, Clinical Modification (ICD-10 CM) diagnosis codes for ST-elevation myocardial infarction (STEMI), non-ST-elevation 
myocardial infarction (NSTEMI), unstable angina (UA), and acute MI (see Table S1 in the electronic supplementary material).

Patients were required to have at least one Medicare or commercial inpatient hospitalization claim for an ACS event between January 1, 2012 and September 30, 2019, to have 1 year of continuous enrollment before this index ACS event, and to have filled a prescription for ticagrelor $(90 \mathrm{mg})$ or clopidogrel $(75 \mathrm{mg}$ or $300 \mathrm{mg}$ ) within 30 days of discharge (index medication). Exclusion criteria were age $<18$ years at the index medication fill date and a prescription for both ticagrelor and clopidogrel within 1 month of discharge. Patients with a prescription for ticagrelor or clopidogrel within 30 days who did not contribute to patient-years (i.e., no prescription covering day 31 or later) were also excluded.

Patients were stratified according to which P2Y12 inhibitor they were prescribed as their index medication (ticagrelor or clopidogrel cohort).

\section{Outcome Measures}

The primary objective of the study was to compare incidence rates and cumulative incidence of inpatient hospitalization for MI in patients with ACS treated with ticagrelor or clopidogrel from day 31 to day 365 (or end of follow-up). Events were identified by ICD-9 CM and ICD-10 CM diagnosis codes during inpatient admissions (see Table S2 in the electronic supplementary material). The primary objective hypothesis was that ticagrelor would be associated with a lower risk of hospitalization for MI than clopidogrel, based on the findings of PLATO. MI was chosen as the efficacy outcome of interest rather than a composite MACE outcome because the Optum CDM database does not capture mortality data for all patients.

The secondary objective was to compare incidence rates and cumulative incidence of inpatient hospitalizations due to major bleeding in the ticagrelor and clopidogrel populations from day 31 to day 365 (or end of followup plus 7 days). Events were identified by ICD-9 $\mathrm{CM}$ and ICD-10 CM diagnosis codes for intracranial, gastrointestinal, pulmonary, urologic, and other major bleeding during inpatient admissions (see Table S3 in the electronic supplementary material). The hypothesis for the secondary objective, based on PLATO, was that ticagrelor would be associated with a higher risk of hospitalization for major bleeding compared with clopidogrel.

Event rates per 100 patient-years for hospitalization for MI and hospitalization for major bleeding were compared without balancing for covariates and also after propensity score matching (PSM) to match patient baseline characteristics and control for event severity. Kaplan-Meier curves were used to plot the incident frequency of hospitalization for MI.

Patients were followed from the index date (day 31 after ACS discharge) until the earliest of the following events, after which they were censored: discontinuation (date of last fill plus number of days of supply and a grace period of 7 days per 30 days of supply); hospitalization for MI (outcome of interest); switching treatment to another P2Y12 inhibitor or a prescription for a lower ticagrelor dose (60 mg); or 365 days after ACS discharge.

The primary and secondary outcomes were also evaluated before and after PSM in patient subgroups, stratified by age $(<65$ years and $\geq 65$ years), PCI procedure for the index ACS event (yes/no), history of type 2 diabetes (T2D; yes/no), and history of chronic kidney disease (CKD; yes/no).

\section{Statistical Methods}

Sample size calculation was done with a twotailed Chi-squared test with an alpha of 0.05 and power of $80 \%$. A minimum of 7714 patients in each cohort was required to provide sufficient power to demonstrate a $16 \%$ relative risk reduction (RRR) for hospitalization for MI, based on the reduction in MI events in the PLATO trial. Descriptive statistics were used to report demographic and clinical characteristics pre- and post-PSM; $P$ values were calculated for the post-PSM populations only.

PSM was used to balance the ticagrelor and clopidogrel cohorts by adjusting for differences 
in baseline demographic variables (patient characteristics and medical history) at the time of the index ACS event (Table S4 in the electronic supplementary material). Correlation among covariables was assessed before PSM, and highly correlated variables were combined using feature engineering or removed. PSM was performed using 1:3 neighbor matching with a 0.01 caliper value. The PSM method aimed to capture as many patients from the clopidogrel population as possible while ensuring that the quality of the match was not compromised. A standardized mean difference (SMD) for continuous variables and raw difference for categorical variables with a threshold value of $<0.05$ was used to define balance. Visual inspection was also done using histograms/density plots.

The ticagrelor and clopidogrel cohorts were balanced after PSM (Figure S1 and Table S5 in electronic supplementary material).

Additional sensitivity analyses were performed with exact matching on ACS type and prior history of MI, followed by optimal full matching using all remaining covariates, as described in the electronic supplementary material (Tables S6 and S7).

Statistical analyses were performed using RStudio statistical software cobalt package (RStudio Inc., Boston, MA, USA).

\section{RESULTS}

There were 339,387 patients with Medicare/commercial claims for hospitalization for ACS between January 1, 2012 and September 30,2019 . Of these, 71,592 patients met the inclusion criteria: 14,110 and 57,482 in the ticagrelor and clopidogrel cohorts, respectively (Fig. 1), providing 5219 and 26,457 patientyears of data for the primary end point, respectively; corresponding values for the secondary end point were 5489 and 27,560 patient-years, respectively. After PSM, the ticagrelor and clopidogrel cohorts included 13,373 and 29,656 patients, respectively,

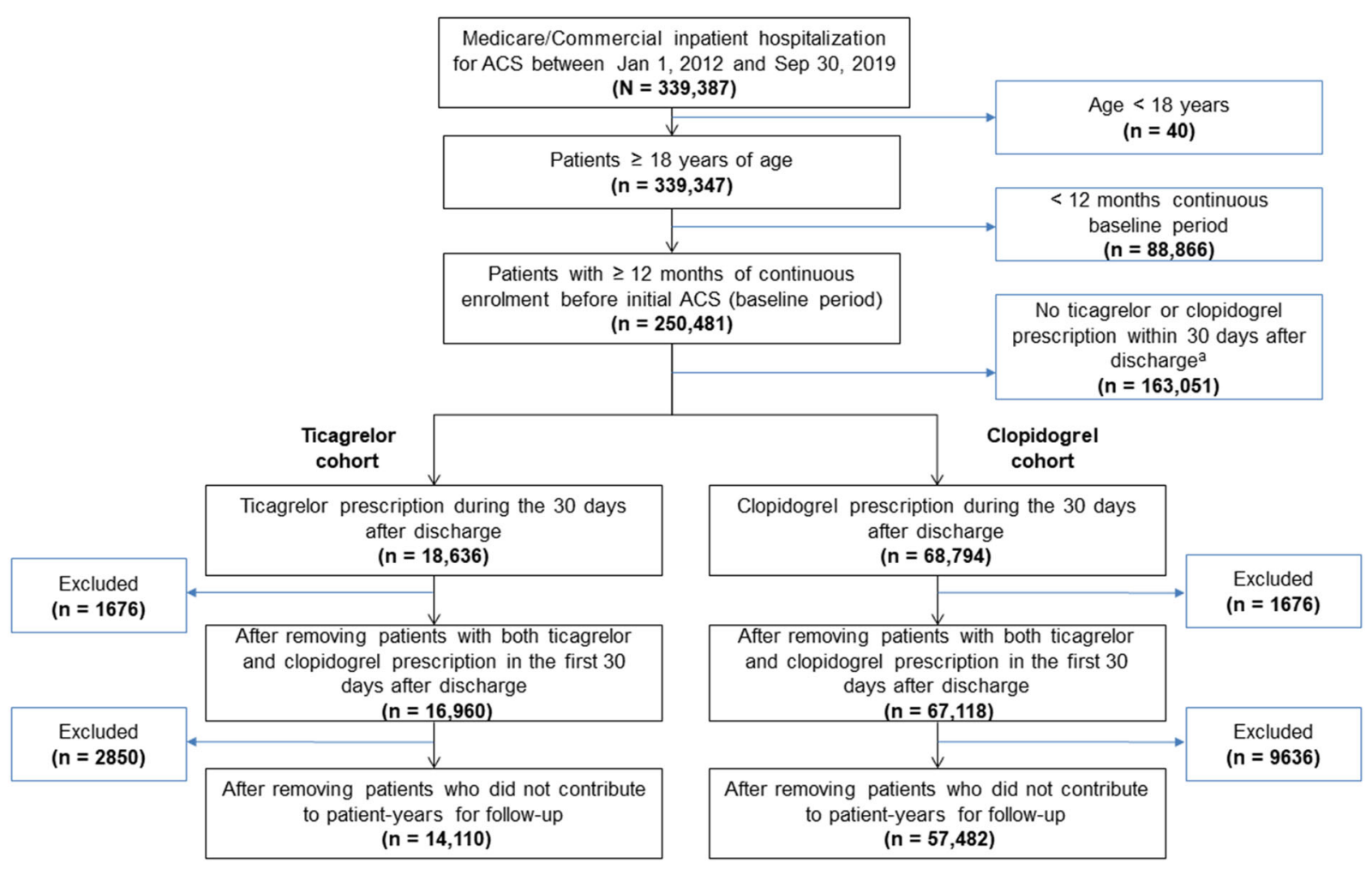

Fig. 1 Patient attrition. $A C S$ acute coronary syndrome. ${ }^{a}$ Includes 10,492 patients with claims for prasugrel 
Table 1 Patient demographics, procedures, and diagnosis covariates before and after propensity score matching

\begin{tabular}{|c|c|c|c|c|c|}
\hline & $\begin{array}{l}\text { Ticagrelor, } \\
\text { pre-PSM } \\
(n=14,110)\end{array}$ & $\begin{array}{l}\text { Clopidogrel, } \\
\text { pre-PSM } \\
(n=57,482)\end{array}$ & $\begin{array}{l}\text { Ticagrelor, } \\
\text { post-PSM } \\
(n=13,373)\end{array}$ & $\begin{array}{l}\text { Clopidogrel, } \\
\text { post-PSM } \\
(n=29,656)\end{array}$ & $\begin{array}{l}\text { Difference }^{a} \\
\text { post-PSM }\end{array}$ \\
\hline Age, years, mean $(\mathrm{SD})$ & $66(12)$ & $70(12)$ & $66(12)$ & $68(12)$ & 0.0134 \\
\hline \multicolumn{6}{|l|}{ Gender } \\
\hline Male & $9700(68.7)$ & $35,561(61.9)$ & $9045(67.6)$ & $19,403(65.4)$ & 0.0034 \\
\hline Female & $4409(31.2)$ & $21,908(38.1)$ & $4327(32.4)$ & $10,253(34.6)$ & -0.0035 \\
\hline Other & $1(0.0)$ & $13(0.0)$ & $1(0.0)$ & $0(0.0)$ & 0.0001 \\
\hline \multicolumn{6}{|l|}{ Region $^{b}$} \\
\hline Midwest & $3525(25.0)$ & $13,933(24.2)$ & $3307(24.7)$ & $7203(24.3)$ & 0.0025 \\
\hline Northeast & $1598(11.3)$ & $7315(12.7)$ & $1549(11.6)$ & $3572(12.0)$ & -0.0006 \\
\hline South & $6539(46.3)$ & $24,583(42.8)$ & $6125(45.8)$ & $13,389(45.1)$ & -0.0033 \\
\hline West & $2436(17.3)$ & $11,586(20.2)$ & $2380(17.8)$ & $5475(18.5)$ & 0.0012 \\
\hline Other & $12(0.1)$ & $65(0.1)$ & $12(0.1)$ & $17(0.1)$ & 0.0003 \\
\hline \multicolumn{6}{|l|}{ Procedure history } \\
\hline PCI & $313(2.2)$ & $1764(3.1)$ & $301(2.3)$ & $750(2.5)$ & -0.0011 \\
\hline CABG & $104(0.7)$ & $995(1.7)$ & $103(0.8)$ & $278(0.9)$ & -0.0001 \\
\hline \multicolumn{6}{|l|}{$\begin{array}{l}\text { Comorbidity (diagnosis } \\
\text { history) }^{c}\end{array}$} \\
\hline Heart failure & $1224(8.7)$ & 9907 (17.2) & $1222(9.1)$ & $3373(11.4)$ & 0.0003 \\
\hline MI & $1319(9.3)$ & $6753(11.7)$ & $1287(9.6)$ & $3139(10.6)$ & -0.0005 \\
\hline Dyslipidemia & $8478(60.1)$ & $39,027(67.9)$ & $8213(61.4)$ & $18,977(64.0)$ & 0.0048 \\
\hline $\mathrm{PAD}$ & $1227(8.7)$ & $9113(15.9)$ & $1218(9.1)$ & $3320(11.2)$ & -0.0001 \\
\hline $\mathrm{T} 2 \mathrm{D}$ & $4640(32.9)$ & $23,068(40.1)$ & $4521(33.8)$ & $10,825(36.5)$ & 0.0022 \\
\hline TIA & $259(1.8)$ & $1968(3.4)$ & $257(1.9)$ & $686(2.3)$ & 0.0001 \\
\hline $\mathrm{AF}$ & $745(5.3)$ & $6300(11.0)$ & $745(5.6)$ & $2114(7.1)$ & -0.0017 \\
\hline Hypertension & $9042(64.1)$ & $42,675(74.2)$ & $8820(66.0)$ & $20,449(69.0)$ & 0.0094 \\
\hline Ischemic stroke & $326(2.3)$ & $2476(4.3)$ & $326(2.4)$ & $903(3.0)$ & -0.0002 \\
\hline CKD & $2288(16.2)$ & $14,018(24.4)$ & $2270(17.0)$ & $5885(19.8)$ & 0.0007 \\
\hline Anemia & $2669(18.9)$ & $16,357(28.5)$ & $2653(19.8)$ & $6835(23.0)$ & 0.0035 \\
\hline $\begin{array}{l}\text { Hospitalization for } \\
\text { major bleeding }\end{array}$ & $811(5.7)$ & $4727(8.2)$ & $790(5.9)$ & $1970(6.6)$ & -0.0002 \\
\hline \multicolumn{6}{|l|}{ CCI score } \\
\hline Mean (SD) & $1.92(2.44)$ & $2.72(2.81)$ & $1.99(2.47)$ & $2.25(2.57)$ & 0.0041 \\
\hline Median & 1 & 2 & 1 & 1 & - \\
\hline
\end{tabular}


Table 1 continued

\begin{tabular}{|c|c|c|c|c|c|}
\hline & $\begin{array}{l}\text { Ticagrelor, } \\
\text { pre-PSM } \\
(n=14,110)\end{array}$ & $\begin{array}{l}\text { Clopidogrel, } \\
\text { pre-PSM } \\
(n=57,482)\end{array}$ & $\begin{array}{l}\text { Ticagrelor, } \\
\text { post-PSM } \\
(n=13,373)\end{array}$ & $\begin{array}{l}\text { Clopidogrel, } \\
\text { post-PSM } \\
(n=29,656)\end{array}$ & $\begin{array}{l}\text { Difference } \\
\text { post-PSM }\end{array}$ \\
\hline \multicolumn{6}{|l|}{ Index date year } \\
\hline 2012 & $299(2.1)$ & $9070(15.8)$ & $299(2.2)$ & $972(3.3)$ & -0.0019 \\
\hline 2013 & $830(5.9)$ & $8639(15.0)$ & $830(6.2)$ & 2651 (8.9) & -0.0041 \\
\hline 2014 & $885(6.3)$ & $7131(12.4)$ & $885(6.6)$ & $2535(8.5)$ & 0.0020 \\
\hline 2015 & $1158(8.2)$ & $6817(11.9)$ & $1158(8.7)$ & $3281(11.1)$ & -0.0011 \\
\hline 2016 & $1474(10.4)$ & $6234(10.8)$ & $1472(11.0)$ & $3735(12.6)$ & -0.0006 \\
\hline 2017 & $2932(21.8)$ & $7191(12.5)$ & $2841(21.2)$ & $5721(19.3)$ & 0.0040 \\
\hline 2018 & $3753(26.6)$ & $7468(13.0)$ & $3375(25.2)$ & $6393(21.6)$ & -0.0042 \\
\hline 2019 & $2779(19.7)$ & $4932(8.6)$ & $2513(18.8)$ & $4368(14.7)$ & 0.0059 \\
\hline \multicolumn{6}{|c|}{ Index ACS type } \\
\hline NSTEMI & $6863(48.6)$ & $35,461(61.7)$ & $6858(51.3)$ & $17,354(58.5)$ & 0.0087 \\
\hline UA & $450(3.2)$ & $6682(11.6)$ & $450(3.4)$ & $1443(4.9)$ & -0.0030 \\
\hline STEMI & $6742(47.8)$ & $15,123(26.3)$ & $6010(44.9)$ & $10,747(36.2)$ & -0.0058 \\
\hline Multiple $^{\mathrm{d}}$ & $55(0.4)$ & $216(0.4)$ & $55(0.4)$ & $112(0.4)$ & - \\
\hline \multicolumn{6}{|l|}{$\begin{array}{l}\text { Concomitant } \\
\text { medications }\end{array}$} \\
\hline Beta-blocker & $1623(11.5)$ & $9005(15.7)$ & $1603(12.0)$ & $3905(13.2)$ & - \\
\hline ACE-I & 3659 (25.9) & $19,197(33.4)$ & $3526(26.4)$ & $9081(30.6)$ & - \\
\hline ARB & $4841(34.3)$ & $23,053(40.1)$ & $4719(35.3)$ & $10,961(37.0)$ & - \\
\hline
\end{tabular}


Table 1 continued

\begin{tabular}{|c|c|c|c|c|c|}
\hline & $\begin{array}{l}\text { Ticagrelor, } \\
\text { pre-PSM } \\
(n=14,110)\end{array}$ & $\begin{array}{l}\text { Clopidogrel, } \\
\text { pre-PSM } \\
(n=57,482)\end{array}$ & $\begin{array}{l}\text { Ticagrelor, } \\
\text { post-PSM } \\
(n=13,373)\end{array}$ & $\begin{array}{l}\text { Clopidogrel, } \\
\text { post-PSM } \\
(n=29,656)\end{array}$ & $\begin{array}{l}\text { Difference } \\
\text { post-PSM }\end{array}$ \\
\hline Statin & $6268(44.4)$ & $30,350(52.8)$ & $6057(45.4)$ & 14.645 & - \\
\hline $\begin{array}{l}\text { Data are } \\
\text { a Stand } \\
\text { b Midw } \\
\text { Wiscons } \\
\text { Island, } \\
\text { Marylan } \\
\text { Alaska, } \\
\text { Wyomir } \\
\text { c Como } \\
\text { CM) an } \\
\text { d Includ } \\
\text { e Post-P } \\
\text { ACE-I a } \\
\text { receptor } \\
M I \text { myo } \\
\text { taneous } \\
\text { infarctio }\end{array}$ & $\begin{array}{l}\text { erwise indicated } \\
\text { rence for contir } \\
\text { a, Iowa, Kansas, } \\
\text { nnecticut, Mass } \\
\text { Alabama, Arkar } \\
\text { rth Carolina, } \\
\text { ia, Colorado, } \\
\text { Rico, Unknown } \\
\text { tified by Intern } \\
\text { assification of D } \\
\text { as of }>1 \text { ACS } \\
\text { relor } n=13,37 \\
\text { ting enzyme inl } \\
\text { ronary artery b } \\
\text { NSTEMI non- } \\
\text { tion, PSM prop } \\
\text { betes, TIA tran }\end{array}$ & $\begin{array}{l}\text { us variables; raw } \\
\text { ichigan, Minneso } \\
\text { usetts, Maine, N } \\
\text {, Delaware, Dis } \\
\text { ahoma, South } \\
\text { yai, Idaho, Mon } \\
\text { onal Classificatio } \\
\text { ses, Tenth Revisic } \\
\text { e } \\
\text { lopidogrel } n=2 \\
\text { tor, } A C S \text { acute } \\
\text { ss grafting, CCI } \\
\text {-elevation myoca } \\
\text { ity score matchir } \\
\text { tt ischemic attac }\end{array}$ & $\begin{array}{l}\text { fference for cate } \\
\text { Missouri, Nortl } \\
\text { Hampshire, Ne } \\
\text { ct of Columbia, } \\
\text { olina, Tennesse } \\
\text { na, Nevada, Ne } \\
\text { f Diseases, Nint } \\
\text { Clinical Modific } \\
657 \\
\text { onary syndrome } \\
\text { arlson's Comorb } \\
\text { ial infarction, } P \\
S D \text { standard de } \\
U A \text { unstable ang }\end{array}$ & $\begin{array}{l}\text { cal variables } \\
\text { akota, Nebraska, } \\
\text { ersey, New York, } \\
\text { orida, Georgia, } \\
\text { exas, Virginia, } \\
\text { Mexico, Oregon } \\
\text { evision, Clinical } \\
\text { on (ICD-10 CM } \\
F \text { atrial fibrillat } \\
\text { y Index, CKD c } \\
\text { peripheral arter } \\
\text { tion, STEMI ST }\end{array}$ & $\begin{array}{l}\text { io, South Dakota, } \\
\text { ansylvania, Rhode } \\
\text { tucky, Louisiana, } \\
\text { Virginia; West: } \\
\text { tah, Washington, } \\
\text { dification (ICD-9 } \\
\text { agnosis codes } \\
\text { ARB angiotensin } \\
\text { ic kidney disease, } \\
\text { sease, } P C I \text { percu- } \\
\text { vation myocardial }\end{array}$ \\
\hline
\end{tabular}

corresponding to 94.8 and $51.6 \%$ of the prePSM cohorts. There were 4945 and 13,895 patient-years of data for the primary end point and 5202 and 14,464 patient-years of data for the secondary end point for the ticagrelor and clopidogrel cohorts, respectively.

The majority of patients were male and the mean age in the ticagrelor and clopidogrel cohorts was 66 and 70 years (66 and 68 years post-PSM), respectively; most patients had no prior history of MI or hospitalization for major bleeding (Table 1). The proportion of patients using anticoagulants during the follow-up period was lower in the ticagrelor cohort than in the clopidogrel cohort. Before PSM, 851 patients $(6.0 \%)$ in the ticagrelor cohort and 6779 patients $(11.8 \%)$ in the clopidogrel cohort were taking anticoagulants; post-PSM values were $830(6.2 \%)$ and $3510(11.8 \%)$, respectively. The mean (standard deviation) duration of anticoagulant use in the post-PSM population was 91
(84) days in the ticagrelor cohort and 120 (100) days in the clopidogrel cohort.

Before PSM, the ticagrelor and clopidogrel cohorts were unbalanced with respect to age, some index years (2012, 2013, 2014, 2017, 2018, and 2019), male gender, Charlson's Comorbidity Index score, some baseline comorbidities (heart failure, dyslipidemia, peripheral artery disease, CKD, T2D, atrial fibrillation, hypertension, and anemia), and some index ACS types (NSTEMI, UA, STEMI) (see Figure S1i and Table S5 in the electronic supplementary material). These covariates were balanced after PSM, as indicated by SMD or raw difference values below the $<0.05$ threshold (see Table S5 in the electronic supplementary material), and similar propensity score distributions for both cohorts (see Figure S1ii in the electronic supplementary material). PSM also produced balanced cohorts for the subgroups analyzed (data not shown). 


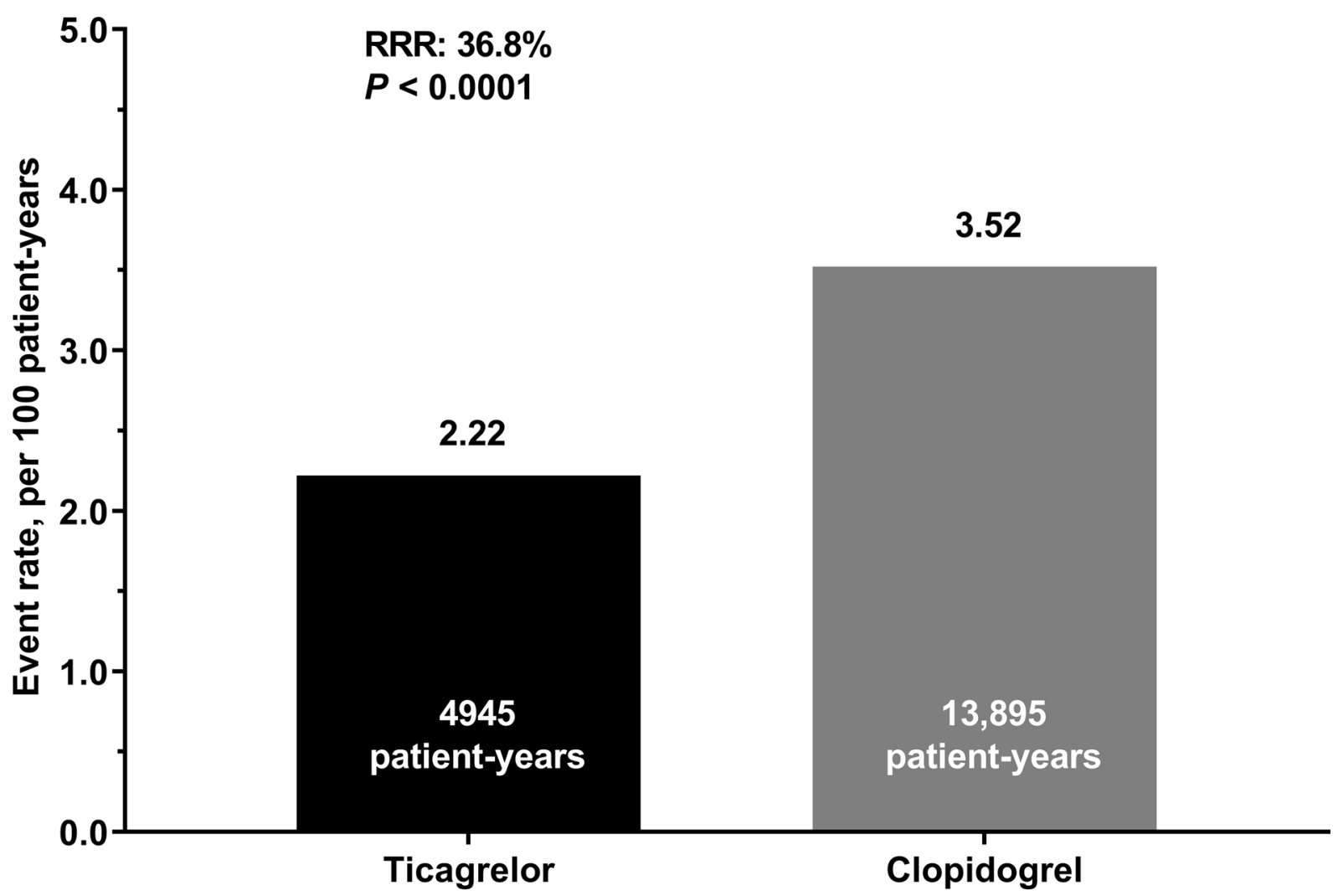

Fig. 2 Hospitalization for MI post-propensity score matching. $M I$ myocardial infarction, $R R R$ relative risk reduction

\section{Hospitalization for Myocardial Infarction}

Hospitalization for MI was lower in the ticagrelor cohort than the clopidogrel cohort, with event rates of 2.17 vs. 4.10 per 100 patient-years (47.3\% RRR) before PSM (see Figure S2i in the electronic supplementary material) and $2.22 \mathrm{vs.}$ 3.52 per 100 patient-years $(36.8 \%$ RRR; $P<0.0001)$ after PSM (Fig. 2). The Kaplan-Meier plot indicated that the probability of survival without hospitalization for MI was significantly greater for the ticagrelor vs. clopidogrel cohort throughout the treatment period $(P<0.0001)$ (Fig. 3).

\section{Hospitalization Due to Major Bleeding}

Hospitalization for major bleeding was lower in the ticagrelor cohort than in the clopidogrel cohort before PSM (event rate 1.95 vs. 2.28 per 100 patient-years; RRR 14.6\%) (see Figure S2ii in the electronic supplementary material).
However, the event rates in the ticagrelor and clopidogrel cohorts were similar after PSM (2.04 vs. 2.06 per 100 patient-years; $1.1 \%$ RRR; $P=0.9214)$ (Fig. 4).

\section{Subgroup Analyses}

Subgroup analyses after PSM indicated that ticagrelor was associated with significant reductions in hospitalization for $\mathrm{MI}$ in the subgroups of patients aged $\geq 65$ years, with PCI for the index ACS event, without T2D, and without CKD, but not for the subgroups with age $<65$ years, without PCI for the index ACS event, with T2D, or with CKD (Fig. 5, see also Table S8 in the supplementary material). Results for subgroups pre-PSM are presented in Table $\$ 9$ in the supplementary material.

There were no statistically significant differences between ticagrelor and clopidogrel for hospitalization due to major bleeding in most subgroups. However, in the subgroup of 


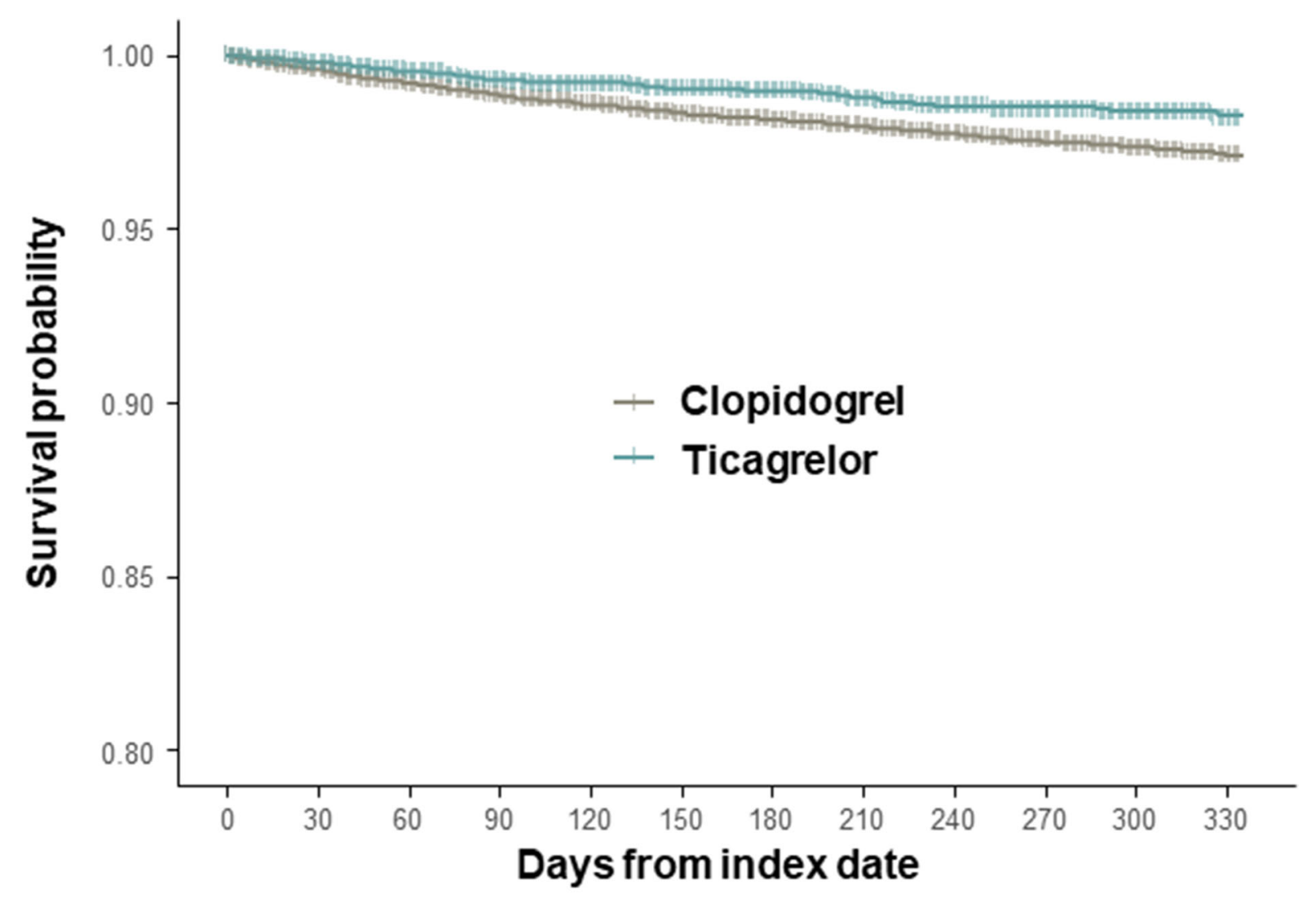

Number at risk

\begin{tabular}{|c|c|c|c|c|c|c|c|c|c|c|c|c|}
\hline Clopidogrel & 29659 & 24853 & 21917 & 18495 & 16479 & 14708 & 12949 & 11609 & 10438 & 9342 & 8426 & 7318 \\
\hline \multirow[t]{3}{*}{ Ticagrelor } & 13371 & 10251 & 8419 & 6900 & 5861 & 5034 & 4247 & 3651 & 3155 & 2704 & 2308 & 1803 \\
\hline & 0 & 30 & 60 & 90 & 120 & 150 & 180 & 210 & 240 & 270 & 300 & 330 \\
\hline & \multicolumn{12}{|c|}{ Days from index date } \\
\hline
\end{tabular}

Cumulative number of events

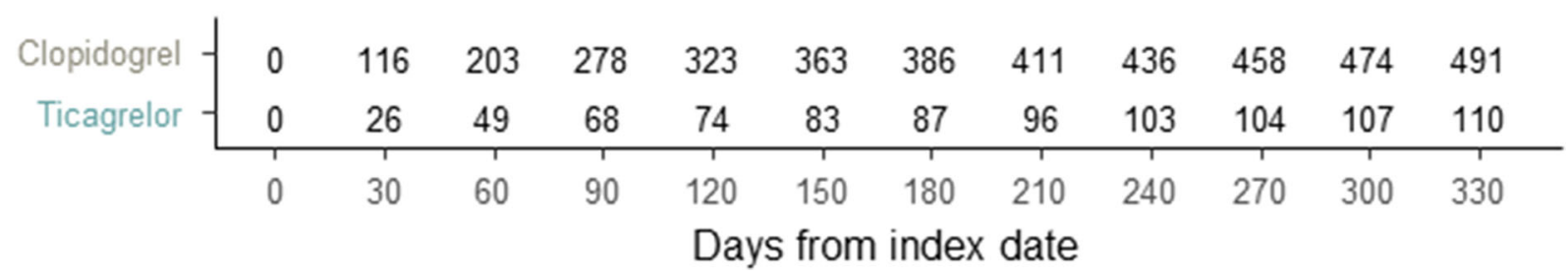

Fig. 3 Kaplan-Meier curve for hospitalization for MI (post-propensity score matching). Log-rank $P$ value: $P<0.0001 . M I$ myocardial infarction

patients who did not undergo PCI for the index ACS event (549 and 1936 patient-years of follow-up for ticagrelor and clopidogrel, respectively), the event rates for ticagrelor and clopidogrel were 4.01 and 2.43 per 100 patientyears, respectively, and the RRR of $-65.0 \%$ favored clopidogrel over ticagrelor $(P=0.0467)$ (see Figure S3 and Table S10 in the electronic 


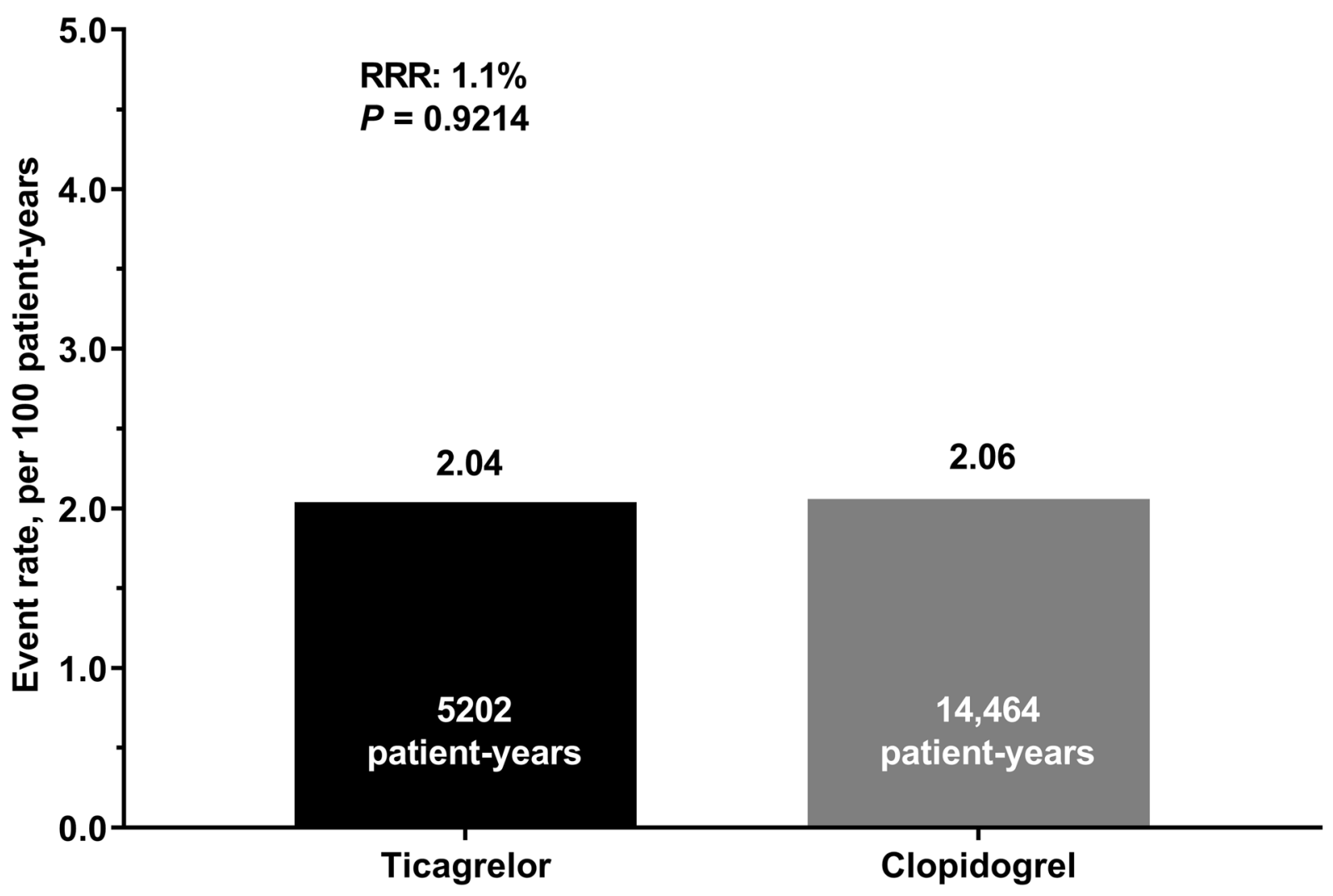

Fig. 4 Hospitalization for major bleeding post-propensity score matching. $R R R$ relative risk reduction

supplementary material). Results for subgroups pre-PSM are presented in Table S11 in the electronic supplementary material.

\section{DISCUSSION}

This is the first on-treatment analysis with the primary objective of comparing hospitalization for MI after an ACS event with ticagrelor and clopidogrel in a US population in a real-world setting. After an ACS event, a significant proportion of patients experience recurrent MACE, including MI $[2,3]$, with consequent clinical and economic impacts. Non-adherence to therapy is a major predictor of developing subsequent cardiovascular events leading to rehospitalization in patients with ACS [14]. This analysis underscores the importance of adherence to the appropriate guideline-recommended therapy, in this case ticagrelor in preference to clopidogrel for at least 12 months
(6-12 months for patients with increased bleeding risk) post-ACS [4]. This study supports the efficacy findings of the PLATO trial [9], and confirms the effectiveness of ticagrelor in a realworld setting.

In this population of patients who were ontreatment with their discharged P2Y12 inhibitor, hospitalization for MI was significantly lower in the overall ticagrelor cohort compared with the clopidogrel cohort. Reductions in hospitalization for MI were also seen with ticagrelor vs. clopidogrel in subgroups of patients aged $\geq 65$ years, without T2D at baseline, without CKD at baseline, and with PCI for the index ACS event.

The reduction in hospitalizations for MI seen with ticagrelor vs. clopidogrel in the overall study population was also not at the expense of an increase in hospitalizations due to major bleeding. There was no significant difference between ticagrelor and clopidogrel in the risk of hospitalization for major bleeding in most of 


\section{Hospitalization for MI RRR (95\% Cl), \%}

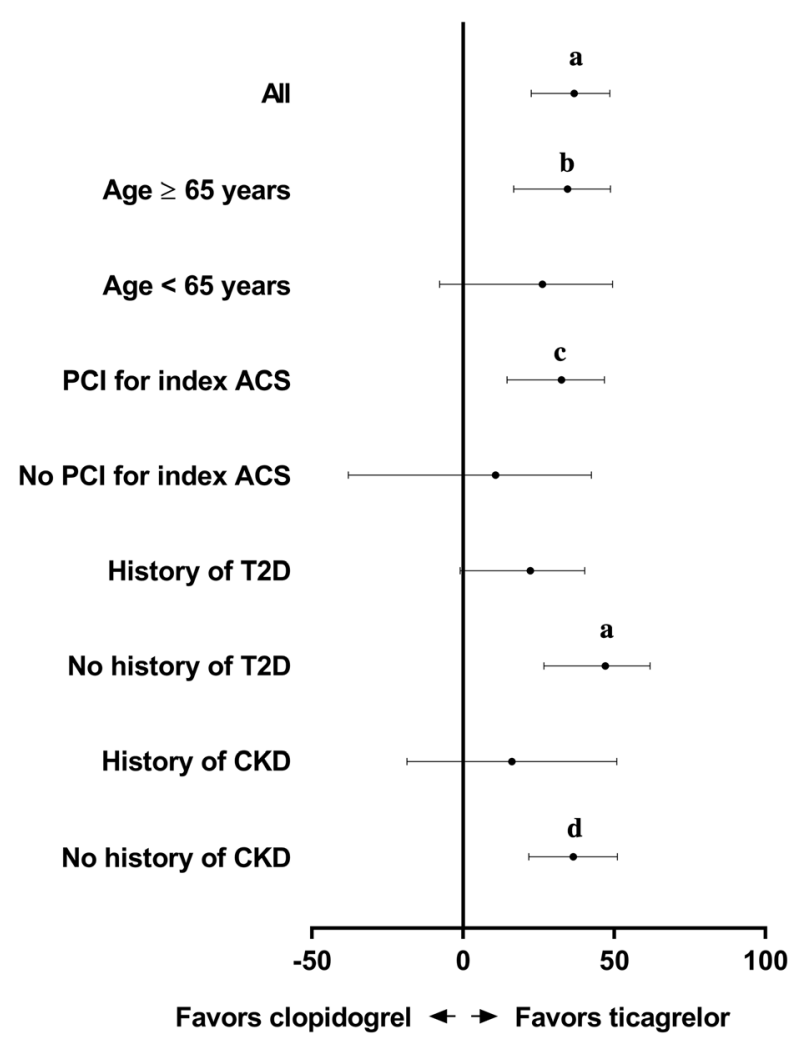

Fig. 5 Hospitalization for MI in patient subgroups postpropensity score matching. $A C S$ acute coronary syndrome, $C K D$ chronic kidney disease (stage 1-5), $M I$ myocardial infarction, $P C I$ percutaneous coronary intervention, $T 2 D$ type 2 diabetes. ${ }^{\mathrm{a}} P<0.0001 ;{ }^{\mathrm{b}} P=0.0005 ;{ }^{\mathrm{c}} P=0.0009$; ${ }^{\mathrm{d}} P=0.0001$

the subgroups studied. The exception was the subgroup of patients who did not undergo PCI for the index ACS event, in which ticagrelor was associated with a higher risk for hospitalization due to major bleeding compared with clopidogrel. However, this should be interpreted with caution due to the small size of this subgroup (549 and 1936 patient-years of follow-up for bleeding for ticagrelor and clopidogrel, respectively).

In the US, prescribing patterns and treatment persistence have presented methodological challenges for real-world head-to-head comparisons. The methods used in this analysis to ensure patients were on-treatment with their discharged index P2Y12 inhibitor throughout the follow-up period, combined with balancing of the cohorts by PSM, overcome some of the potential limitations of real-world observational studies.

Results of this study vary from the findings of earlier real-world studies comparing ticagrelor and clopidogrel, which had the inherent limitations of the ITT analysis methods used. An ITT observational analysis in approximately 11,000 patients with ACS with planned PCI found no significant reduction in hospitalization for ACS with ticagrelor vs. clopidogrel (adjusted HR 0.93; 95\% CI 0.79-1.09) 365 days after the index ACS hospitalization [13]. However, major bleeding was increased with ticagrelor vs. clopidogrel [13]. Similarly, the SWEDEHEART study reported readmission for MI at 24 months was lower with ticagrelor vs. clopidogrel, although the difference was not statistically significant after adjustment for confounders (adjusted HR 0.89; 95\% CI 0.78-1.01) [10]. The study also reported that bleeding requiring admission occurred more frequently with ticagrelor vs. clopidogrel over 24 months [10].

The findings of this study highlight the importance of adherence and persistence with guideline-recommended antiplatelet therapy for the reduction of hospitalization for MI postACS. However, despite guideline recommendations for DAPT for at least 12 months (6-12 months for patients with increased bleeding risk) post-ACS with ticagrelor in preference to clopidogrel [4], a significant proportion of patients discontinue P2Y12 inhibitor therapy within 1 year [15-18]. Furthermore, de-escalation of P2Y12 inhibitor therapy, from ticagrelor or prasugrel to clopidogrel, occurs relatively frequently $[19,20]$. Early discontinuation of DAPT has been found to be associated with an increased risk of MACE [17, 18]; therefore, efforts to improve adherence (including addressing affordability for patients) [16, 21], and maintaining patients on more potent P2Y12 inhibitors have the potential to improve outcomes in patients with ACS without the expense of hospitalization due to major bleeding. 


\section{Study Strengths and Limitations}

The Optum CDM database provides longitudinal data from a large sample ( $>90$ million patients, $>150,000$ health care providers), allowing adequate sample sizes for the ACS population and ticagrelor and clopidogrel cohorts. The study population was representative of insured patients in the US, and the results are therefore likely generalizable to this population but not to uninsured patients.

Censoring patients after discontinuation based on the date of the last fill plus a 7-day grace period for every 30 days of supply was a proxy for persistence with treatment. Patients switching from their index medication were also censored, preventing categorization of patients to a medication cohort without having received that medication during the treatment period, as is likely in an ITT observational analysis. This was particularly important for this study because patients are frequently de-escalated from ticagrelor to clopidogrel in clinical practice [22].

This study has limitations inherent to retrospective analyses and the use of claims-based data. Prescription claims recorded in the Optum CDM database can only account for distribution of medication, not actual use. Use of over-thecounter medications such as aspirin was not captured; therefore, DAPT was inferred as per US treatment guidelines for ACS [4].

The Optum CDM database did not report mortality information for all patients. However, the discontinuation criteria ensured consistent prescriptions for ticagrelor or clopidogrel during the follow-up period, which increased the likelihood of patients being alive and on treatment. The lack of mortality data also meant that mortality due to non-MI events during the follow-up period was not captured. Therefore, the incidence of vascular death in the ticagrelor and clopidogrel cohorts could not be compared; however, it is unlikely that vascular death would be higher with ticagrelor, based on the results of the PLATO study [9]. No difference in non-cardiovascular mortality was expected, as this was not observed in PLATO [9].

Although the study cohorts appeared balanced after PSM, there is a possibility of residual confounding effects that cannot be controlled with PSM, and it is not possible to determine the potential effect of unmeasured covariates on treatment selection or outcomes [23].

\section{CONCLUSIONS}

This real-world on-treatment analysis showed that among patients with ACS that persisted with treatment, hospitalization for MI was significantly reduced with ticagrelor compared with clopidogrel, with no significant difference in hospitalization for bleeding. These findings in a real-world contemporary US ACS population highlight the importance of adherence to guideline-recommended antiplatelet therapy post-ACS.

\section{ACKNOWLEDGEMENTS}

Funding. This study was funded by AstraZeneca. AstraZeneca also funded the journal's Rapid Service Fee.

Authorship. All named authors meet the International Committee of Medical Journal Editors (ICMJE) criteria for authorship for this article, take responsibility for the integrity of the work as a whole, and have given their approval for this version to be published.

Author Contributions. TO, NA, NB, DB, and NDK contributed to the study conception. All authors contributed to the study design. KC contributed to the data analysis. All authors contributed to data interpretation. All authors provided critical review of manuscript drafts and approved the final manuscript.

Medical Writing, Editorial, and Other Support. Raewyn M. Poole of inScience Communications, Springer Healthcare, provided medical writing support in accordance with good publication practice (GPP-3) funded by AstraZeneca. Jared Woo of ZS Associates acted as the study advisor. ZS Associates was contracted by AstraZeneca to assist in the 
development and analysis of this study; this work was performed independently of the study sponsor. AstraZeneca employees James Eudicone (statistical assistance), Eva Lesen (review of study protocol), and Hungta Chen (review of study protocol) provided additional support.

Disclosures. Drs Tope Olufade, Narinder Bhalla, John Venditto, and Naeem D. Khan and Mr Durgesh Bhandary are employees and stockholders of AstraZeneca. Dr Nipun Atreja was an employee of AstraZeneca at the time the study was conducted and is currently an employee of Bristol Myers Squibb (Lawrence Township, NJ, USA). Dr David Cobden was an employee of AstraZeneca at the time the study was conducted and is currently an employee of Genentech (San Francisco, CA, USA). Mr Kaushik Chafekar is an employee of ZS Associates. ZS Associates was engaged by AstraZeneca to assist with the development and analysis of this study.

Compliance with Ethics Guidelines. Institutional Review Board approval and written informed consent from patients were not required because this study used only de-identified claims data. The data source for this study was the Optum $^{\mathrm{TM}}$ Clinformatics ${ }^{\mathrm{TM}}$ database, which can be accessed by license from Optum (https://www.optum.com/business/solutions/ life-sciences.html).

Data Availability. All data generated or analyzed during this study are included in this published article or as supplementary information files.

Open Access. This article is licensed under a Creative Commons Attribution-NonCommercial 4.0 International License, which permits any non-commercial use, sharing, adaptation, distribution and reproduction in any medium or format, as long as you give appropriate credit to the original author(s) and the source, provide a link to the Creative Commons licence, and indicate if changes were made. The images or other third party material in this article are included in the article's Creative Commons licence, unless indicated otherwise in a credit line to the material. If material is not included in the article's Creative Commons licence and your intended use is not permitted by statutory regulation or exceeds the permitted use, you will need to obtain permission directly from the copyright holder. To view a copy of this licence, visit http://creativecommons.org/licenses/by$\mathrm{nc} / 4.0 /$.

\section{REFERENCES}

1. Virani SS, Alonso A, Benjamin EJ, et al. Heart disease and stroke statistics-2020 update: a report from the American Heart Association. Circulation. 2020;141:e139-596.

2. Jernberg $\mathrm{T}$, Hasvold $\mathrm{P}$, Henriksson $\mathrm{M}$, Hjelm $\mathrm{H}$, Thuresson $M$, Janzon $M$. Cardiovascular risk in post-myocardial infarction patients: nationwide real world data demonstrate the importance of a long-term perspective. Eur Heart J. 2015;36: 1163-70.

3. Smolina K, Wright FL, Rayner M, Goldacre MJ. Long-term survival and recurrence after acute myocardial infarction in England, 2004 to 2010. Circ Cardiovasc Qual Outcomes. 2012;5:532-40.

4. Levine GN, Bates ER, Bittl JA, et al. 2016 ACC/AHA guideline focused update on duration of dual antiplatelet therapy in patients with coronary artery disease: a report of the American College of Cardiology/American Heart Association Task Force on Clinical Practice Guidelines: an update of the 2011 ACCF/AHA/SCAI guideline for percutaneous coronary intervention, 2011 ACCF/AHA guideline for coronary artery bypass graft surgery, 2012 ACC/ AHA/ACP/AATS/PCNA/SCAI/STS guideline for the diagnosis and management of patients with stable ischemic heart disease, 2013 ACCF/AHA guideline for the management of ST-elevation myocardial infarction, 2014 AHA/ACC guideline for the management of patients with non-ST-elevation acute coronary syndromes, and 2014 ACC/AHA guideline on perioperative cardiovascular evaluation and management of patients undergoing noncardiac surgery. Circulation. 2016;134:e123-55.

5. Husted S, Emanuelsson H, Heptinstall S, Sandset PM, Wickens M, Peters G. Pharmacodynamics, pharmacokinetics, and safety of the oral reversible P2Y12 antagonist AZD6140 with aspirin in patients with atherosclerosis: a double-blind comparison to clopidogrel with aspirin. Eur Heart J. 2006;27: 1038-47. 
6. Storey RF, Husted S, Harrington RA, et al. Inhibition of platelet aggregation by AZD6140, a reversible oral P2Y12 receptor antagonist, compared with clopidogrel in patients with acute coronary syndromes. J Am Coll Cardiol. 2007;50:1852-6.

7. Collet J, Thiele H, Barbato E, et al. 2020 ESC Guidelines for the management of acute coronary syndromes in patients presenting without persistent ST-segment elevation. Eur Heart J. 2021;42: 1289-367.

8. Ibanez B, James S, Agewall S, et al. 2017 ESC guidelines for the management of acute myocardial infarction in patients presenting with ST-segment elevation: the task force for the management of acute myocardial infarction in patients presenting with ST-segment elevation of the European Society of Cardiology (ESC). Eur Heart J. 2018;39:119-77.

9. Wallentin L, Becker RC, Budaj A, et al. Ticagrelor versus clopidogrel in patients with acute coronary syndromes. N Engl J Med. 2009;361:1045-57.

10. Sahlen A, Varenhorst C, Lagerqvist B, et al. Outcomes in patients treated with ticagrelor or clopidogrel after acute myocardial infarction: experiences from SWEDEHEART registry. Eur Heart J. 2016;37:3335-42.

11. Hernan MA, Hernandez-Diaz S. Beyond the intention-to-treat in comparative effectiveness research. Clin Trials. 2012;9:48-55.

12. Toh S, Hernan MA. Causal inference from longitudinal studies with baseline randomization. Int $\mathrm{J}$ Biostat. 2008;4:22.

13. Turgeon RD, Koshman SL, Youngson E, et al. Association of ticagrelor vs clopidogrel with major adverse coronary events in patients with acute coronary syndrome undergoing percutaneous coronary intervention. JAMA Intern Med. 2020;180:420-8.

14. Huber CA, Meyer MR, Steffel J, Blozik E, Reich O, Rosemann T. Post-myocardial infarction (MI) care: medication adherence for secondary prevention after MI in a large real-world population. Clin Ther. 2019;41:107-17.

15. Czarny MJ, Nathan AS, Yeh RW, Mauri L. Adherence to dual antiplatelet therapy after coronary stenting: a systematic review. Clin Cardiol. 2014;37:505-13.
16. Doll JA, Hellkamp AS, Goyal A, Sutton NR, Peterson ED, Wang TY. Treatment, outcomes, and adherence to medication regimens among dual MedicareMedicaid-eligible adults with myocardial infarction. JAMA Cardiol. 2016;1:787-94.

17. Fosbol EL, Ju C, Anstrom KJ. Early cessation of adenosine diphosphate receptor inhibitors among acute myocardial infarction patients treated with percutaneous coronary intervention: insights from the TRANSLATE-ACS Study (Treatment With Adenosine Diphosphate Receptor Inhibitors: Longitudinal Assessment of Treatment Patterns and Events After Acute Coronary Syndrome). Circ Cardiovasc Interv. 2016;9:e003602.

18. Mehran R, Baber U, Steg PG, et al. Cessation of dual antiplatelet treatment and cardiac events after percutaneous coronary intervention (PARIS): 2 year results from a prospective observational study. Lancet. 2013;382:1714-22.

19. Motovska Z, Hlinomaz O, Kala P, et al. 1-year outcomes of patients undergoing primary angioplasty for myocardial infarction treated with prasugrel versus ticagrelor. J Am Coll Cardiol. 2018;71: 371-81.

20. Zettler ME, Peterson ED, McCoy LA, et al. Switching of adenosine diphosphate receptor inhibitor after hospital discharge among myocardial infarction patients: insights from the Treatment with Adenosine Diphosphate Receptor Inhibitors: Longitudinal Assessment of Treatment Patterns and Events after Acute Coronary Syndrome (TRANSLATE-ACS) observational study. Am Heart J. 2017;183:62-8.

21. Wang TY, Kaltenbach LA, Cannon CP. Effect of medication co-payment vouchers on P2Y12 inhibitor use and major adverse cardiovascular events among patients with myocardial infarction: the ARTEMIS randomized clinical trial. JAMA. 2019;321:44-55.

22. Angiolillo DJ, Patti G, Chan KT, et al. De-escalation from ticagrelor to clopidogrel in acute coronary syndrome patients: a systematic review and metaanalysis. J Thromb Thrombolysis. 2019;48:1-10.

23. Brooks JM, Ohsfeldt RL. Squeezing the balloon: propensity scores and unmeasured covariate balance. Health Serv Res. 2013;48:1487-507. 